\title{
Research on Cutting Patterns for Cutting Head of Longitudinal Axial Roadheader
}

Xiaoming Yuan ${ }^{1,2,3, a}$, Peng Yan ${ }^{1,2, b}$, Lele Yang
Zhang ${ }^{1,2, c, e^{*}}$, Xuemei Zong
1,2,3,d and Lijie

${ }^{1}$ Hebei Provincial Key Laboratory of Heavy Machinery Fluid Power Transmission and Control,

Yanshan University, Qinhuangdao, Hebei, 066004

${ }^{2}$ Key Laboratory of Advanced Forging \& Stamping Technology and Science,

Yanshan University, Qinhuangdao, Hebei, 066004

${ }^{3}$ Jiangsu Xuzhou Construction Machinery Research Institute, Xuzhou, Jiangsu, 221004

axiaomingbingbing@163.com, byanpeng0620@126.com, c1045019034@qq.com,

dzongxm@xcmg.com, e zhangljys@126.com

Keywords: longitudinal axial roadheader; cutting head; drilling condition; swing condition; cutting patterns.

Abstract. The cutting patterns of cutting process is drawn for cutting head of longitudinal axial roadheader. The changing of cutting groove shape, the coal lumpiness and partial load coefficient can be obtained intuitively by observing the cutting patterns. Cutting performances under different conditions of the deflection angles, drilling speeds and swing speeds are analyzed, which provides the basis for the design and analysis of cutting head of longitudinal axial roadheader.

\section{Introduction}

As a mechanical versatile excavation equipment, longitudinal axial roadheader has a wide range of applications for mine production, tunnelling and other industry. The design capacity of the roadheader indicates the level of the development of industry in a country. The cutting head is a key part used to cut coal. The cutting patterns can be used as a method to evaluate the cuttability, such as the cutting function angle and the cutting teeth arrangement. The cutting patterns are used to observe the size and shape of briquette cut by each cutting tooth of the cutting head. Based on the area of cutting polygon, the qualitative analysis of the force on each cutting tooth has done, which has been used to judge whether the cutting ability is fully used or overloaded. Based on the length ratio of the two groove lines, whether the cutting teeth have a partial load is certified $^{[1]}$.

Based on the laboratory and in-situ experiments, B.Tiryaki et al. ${ }^{[2]}$ have developed the new computer programs VAP with the aspects of multi-tracking, the simulation results agree with the laboratory and in-situ studies very well. Through developing the stand-alone and network versions in Microsoft Visual Basic programming language, Sriradha Somanchi et al. ${ }^{[3]}$ have presented the results of a research project on the development of lacing and breakout patterns used in the mechanical design of shearer drums. Y. Sun et al. ${ }^{[4]}$ improved the computational accuracy of DOC(the depth of cut) by taking drum advance speed, breakout patterns, the interactions between cutting teeth and the profiles of cutting teeth into account. In addition, they also used the designed models to calculate forces of cutting teeth and whole drum more accurately. Xiubao Shi et al. ${ }^{[5]}$ have programmed to simulate the process of cutting head and draw the cutting patterns, and the program is utilized to quickly judge whether the cutting parameters of the cutting teeth arrangement are reasonable or not. Base on the working conditions and chip shapes, Yongri Cong et al. ${ }^{[6]}$ have proposed to use the cutting patterns to calculate the depth of cut, and the simulation result is more realistic compared to the actual working condition. Xiaohong $\mathrm{Ma}^{[7]}$ has developed cutting patterns program of the continuous miner in 
different conditions, which could checkout the reasonability of the continuous miner and offer effective method for the design.

Their study of cutting patterns provides a certain reference for the cutting teeth arrangement, which laid the foundation for the design of the cutting head. However, their study of cutting patterns still has shortcomings. In this paper, based on the achievements of former researchers, the cutting process simulation model of cutting head of longitudinal axial roadheader is established and the cutting patterns under the conditions of different parameters are obtained. According to the simulation results, the characteristics and performances of longitudinal axial roadheader are analyzed.

\section{The analysis of cutting patterns under different deflection angle $\alpha$.}

Related angle parameters of cutting patterns are shown in Fig.1. P is the axis line of the cutting head, A is envelope line of the spherical cap section, $\mathrm{B}$ is the envelope line of conical section, $\mathrm{C}$ is the envelope line of cylindrical section and $\mathrm{D}$ is the big surface at the bottom. $\Pi$ is the plane across the axis line of cutting head $\mathrm{P}$ and the teeth sharp point. $\mathrm{L}_{1}$ is the projective line of the cutting teeth axis in the $\Pi$ plane, and is perpendicular to tangent line of envelope line. $\beta_{1}$ is the cutting teeth installation angle. $\mathrm{L}_{2}$ is also the projective line of the cutting teeth axis in the $\Pi$ plane, which is formed by turning $\alpha$ angle around point $\mathrm{O}$ from $\mathrm{L}_{1}$. The angle $\alpha$ is called deflection angle, and the cutting teeth sloping angle is $\beta_{2}$.

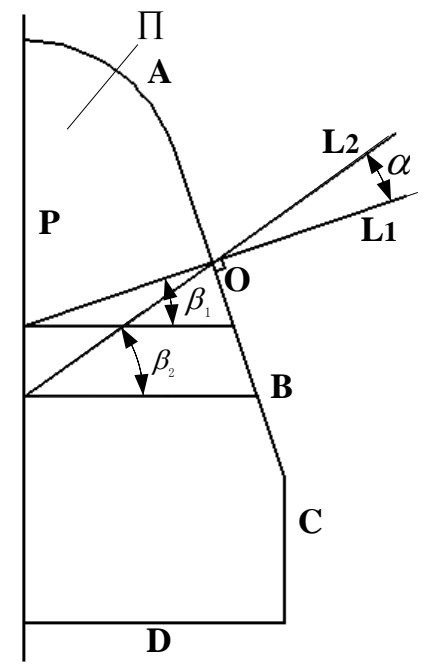

FIGURE.1 The diagram of related angles of cutting patterns

The coal caving angle is $45^{\circ}$. The rotational speed of cutting head is $46 \mathrm{r} / \mathrm{min}$. When the deflection angle $\alpha$ change from $0^{\circ}$ to $20^{\circ}$, the cutting patterns under drilling condition are shown respectively in Fig.2, and the cutting patterns under swing condition are shown respectively in Fig.3.

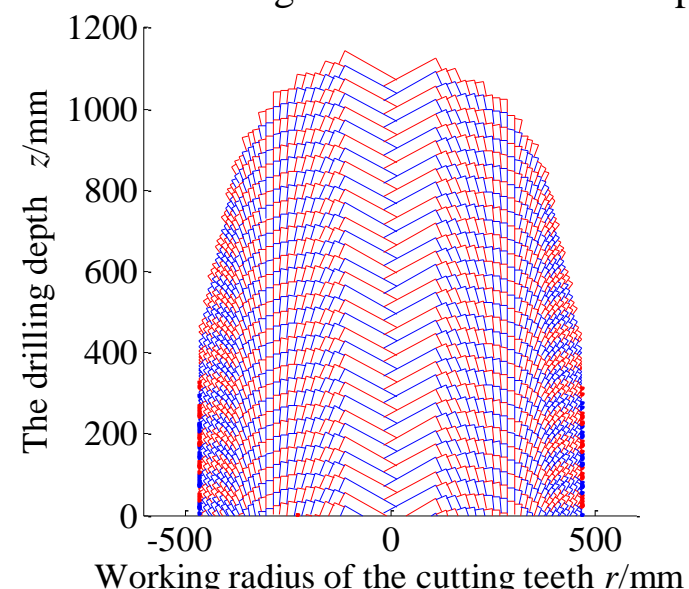

a) $\alpha=0^{\circ}$

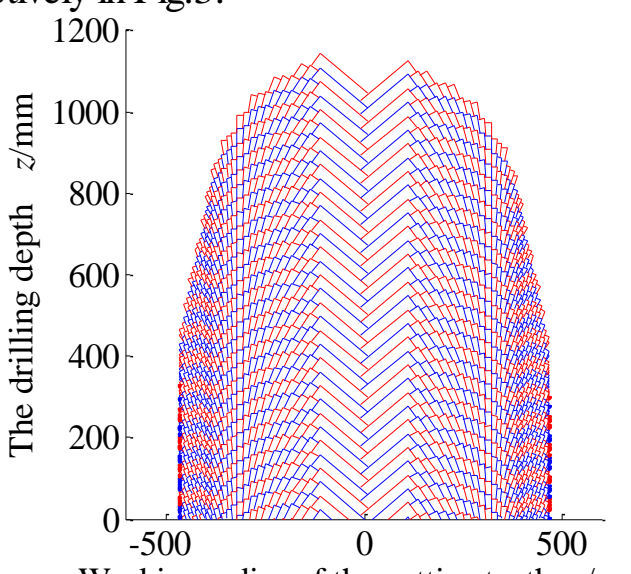

Working radius of the cutting teeth $r / \mathrm{mm}$

b) $\alpha=10^{\circ}$ 


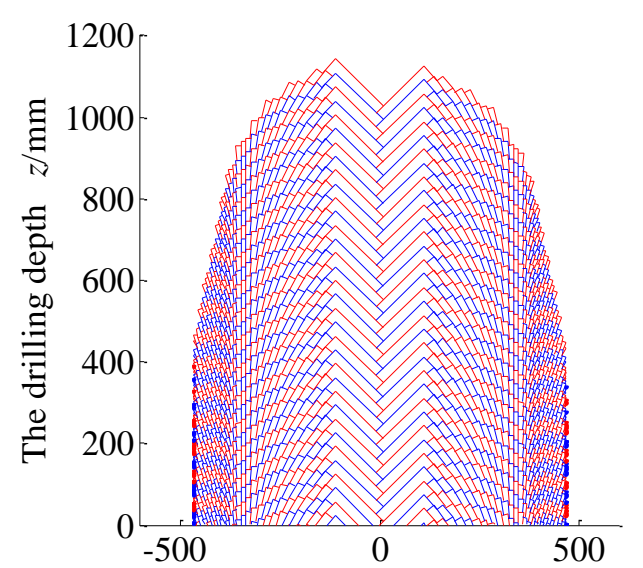

Working radius of the cutting teeth $\mathrm{r} / \mathrm{mm}$ c) $\alpha=15^{\circ}$

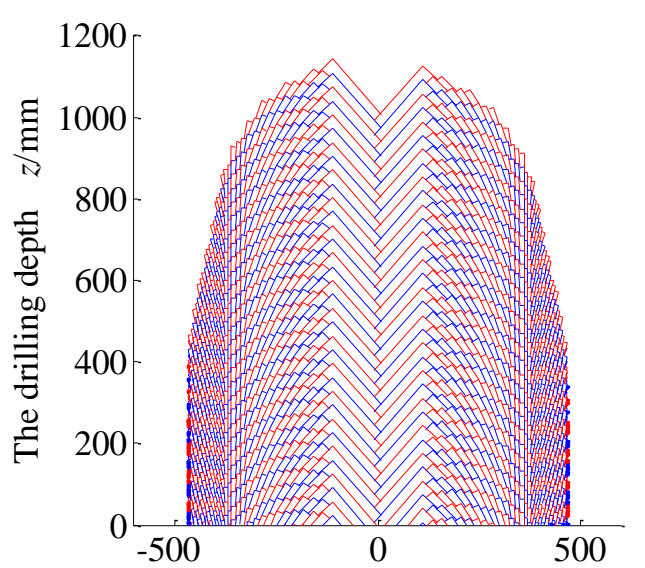

Working radius of the cutting teeth $\mathrm{r} / \mathrm{mm}$

d) $\alpha=20^{\circ}$

FIGURE. 2 Cutting patterns under drilling condition with different deflection angle $\alpha$

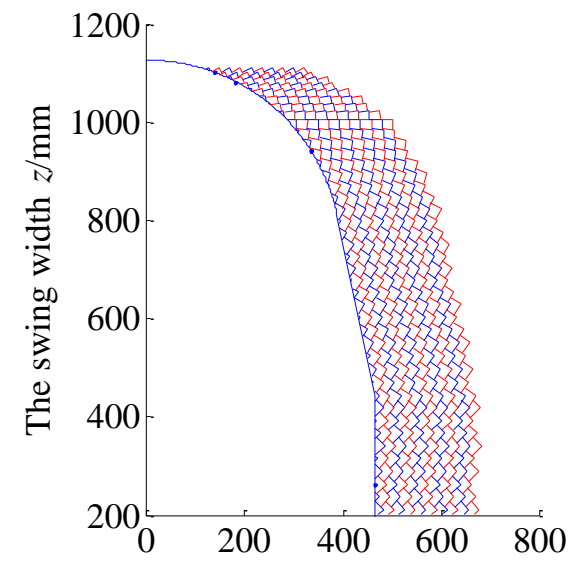

Working radius of the cutting teeth $\mathrm{r} / \mathrm{mm}$

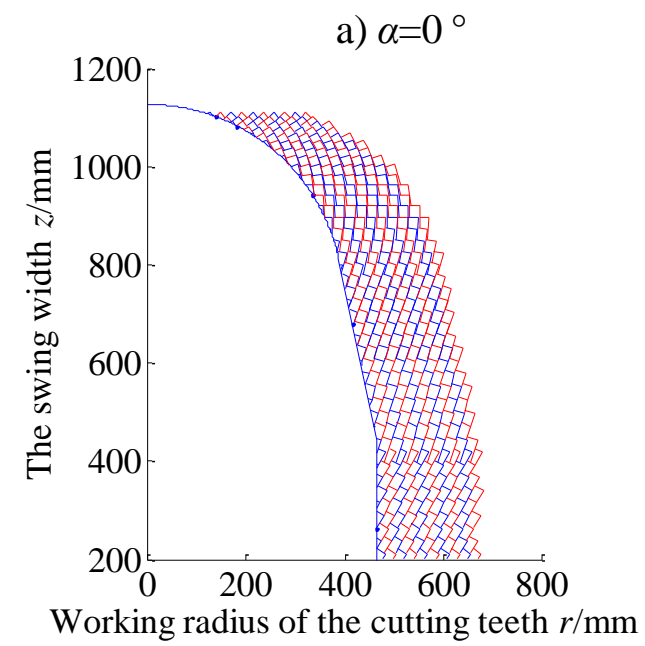

c) $\alpha=15^{\circ}$

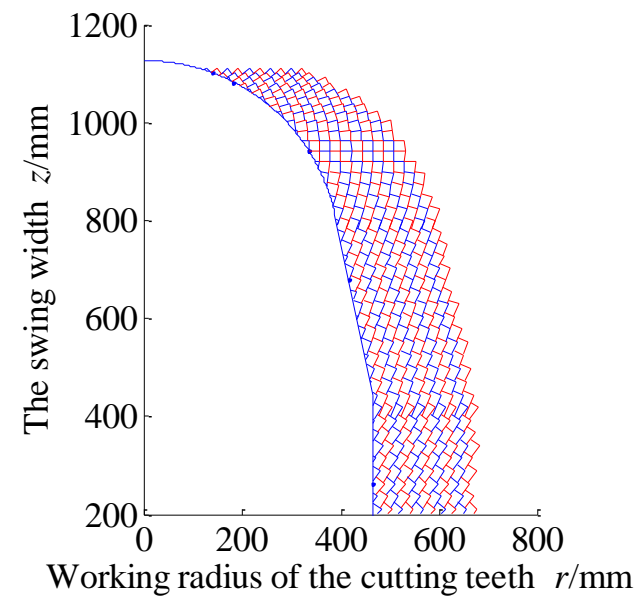

b) $\alpha=10^{\circ}$

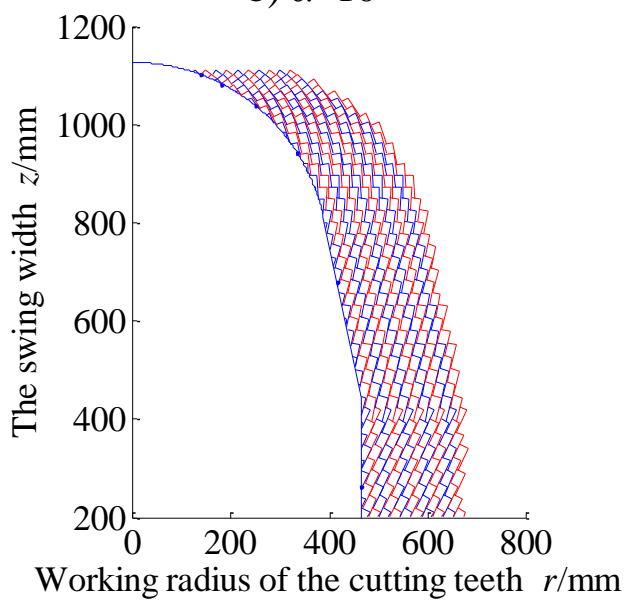

d) $\alpha=20^{\circ}$

FIGURE.3 Cutting patterns under swing condition with different deflection angle $\alpha$

The Fig. 2 and Fig. 3 show that deflection angle $\alpha$ has a big effect on cutting process under drilling condition and swing condition. Under drilling condition, the corresponding chip area in spherical cap section is larger, which is smaller in conical section and smallest in cylindrical section, therefore, the main cutting section is sphericalcap section, and the auxiliary cutting section is conical section and cylindrical section. Under swing condition, the corresponding chip area in the conical section and cylindrical section is larger, which is smaller in spherical cap section, therefore, the main cutting section is conical section and cylindrical section, and the auxiliary cutting section is spherical cap section. 
When the deflection angle $\alpha$ increases from $0^{\circ}$ to $20^{\circ}$, the chip becomes slender and slender, and the differences of the lengths between the two groove lines become greater and greater, which shows that the partial load of cutting teeth become more serious, and will have a large effect on the service life of the cutting teeth. What's more, with the increase of the deflection angle $\alpha$, nonuniformity of chip blocks increases, which make the cutting head block easily and the phenomenon of machine locking easily appear. Meanwhile, tiny coal will produce too much dust and make the condition of working environment become worse.

When the deflection angle $\alpha$ is $0^{\circ}$, the cross-section is close to square shape, the chip size is more uniform, the dust is less, and the force on either side of cutting teeth is close to equal. Therefore, the best deflection angle $\alpha$ is about $0^{\circ}$.

\section{The analysis of cutting patterns under different drilling speeds.}

When the drilling speed of cutting head $V_{\mathrm{z}}$ change from $0.5 \mathrm{~m} / \mathrm{min}$ to $2.0 \mathrm{~m} / \mathrm{min}$, the cutting patterns under drilling condition are shown respectively in Fig.4. The Fig.4 shows that the drilling speed has a direct effect on cutting patterns. The cutting thickness, chip size, and producing dust capacity are also various with different drilling speeds.

With the increase of drilling speed, the thickness of cut and coal lumpiness will increase and cutting resistance of cutting teeth become bigger, but producing dust capacity will decrease. If drilling speed is too fast, cutting resistance will be excessive, which can cause the cutting head can't move and influence the normal operation of roadheader. Conversely, if drilling speed is too small, cutting resistance become smaller, and then the relationship between cutting teeth and coal is in the grinding state. Moreover, smaller coal lumpiness and more producing dust will deteriorate working environment and be detrimental to the health of workers. Therefore, the best drilling speed of cutting head $V_{\mathrm{z}}$ is about $1.5 \mathrm{~m} / \mathrm{min}$ for the initial design parameters.
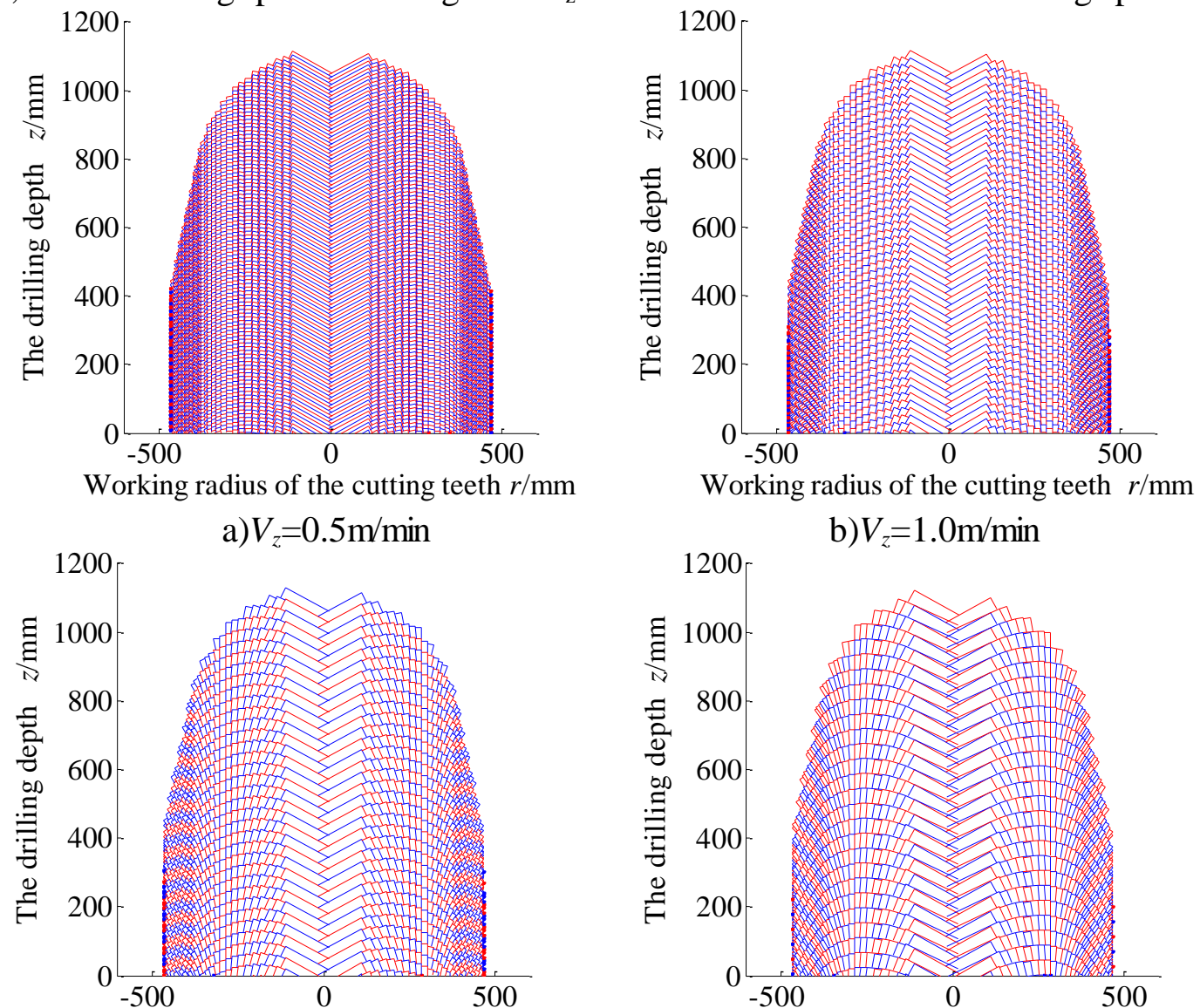

Working radius of the cutting teeth $r / \mathrm{mm}$ c) $V_{z}=1.5 \mathrm{~m} / \mathrm{min}$

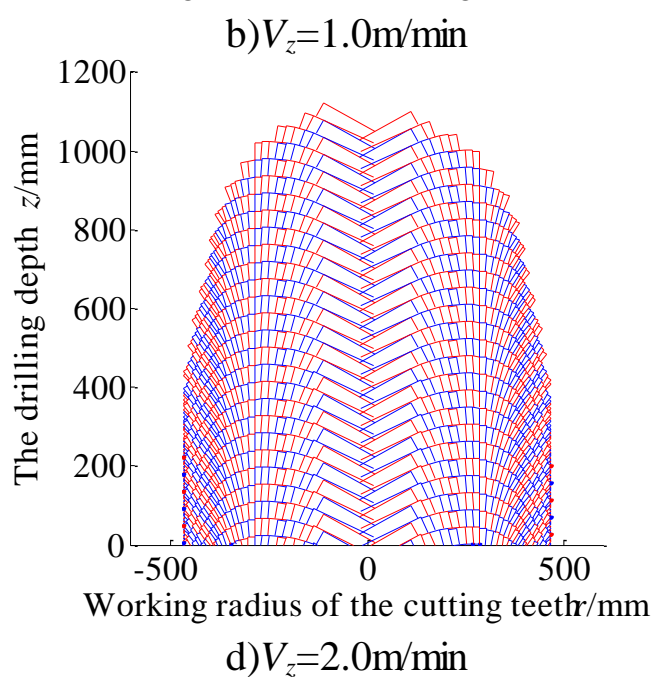

FIGURE.4 Cutting patterns under drilling condition with different drilling speeds 


\section{The analysis of cutting patterns under different swing speeds.}

When the swing speed of cutting head $V_{\mathrm{h}}$ change from $1.0 \mathrm{~m} / \mathrm{min}$ to $4.0 \mathrm{~m} / \mathrm{min}$, the cutting patterns under swing condition are shown respectively in Fig. 5 . The Fig. 5 shows that swing speed also has a direct effect on cutting patterns. The swing speed of cutting head in swing condition is similar to the drilling speed in drilling condition.

If the swing speed is smaller, the cutting thickness, cutting resistance and coal lumpiness are smaller, and unilateral frictional phenomenon will be arisen, therefore, the productivity of the roadheader will be reduced, and the producing dust capacity will be increased greatly, which lead to working environment deteriorate. With the swing speed improving, the coal lumpiness increases and the producing dust capacity decreases. However, if the swing speed is bigger, the cutting quantity of the cutting teeth on both sides will be unequal and produce more lateral load. With the cutting thickness increasing, the cutting exterior force resistance will increase, and cutting teeth may be overloaded. Therefore, the swing speed of cutting head can be chosen reasonably according to the cutting patterns, and the best swing speed of cutting head $V_{\mathrm{h}}$ is about $3.0 \mathrm{~m} / \mathrm{min}$ for the initial design parameters.
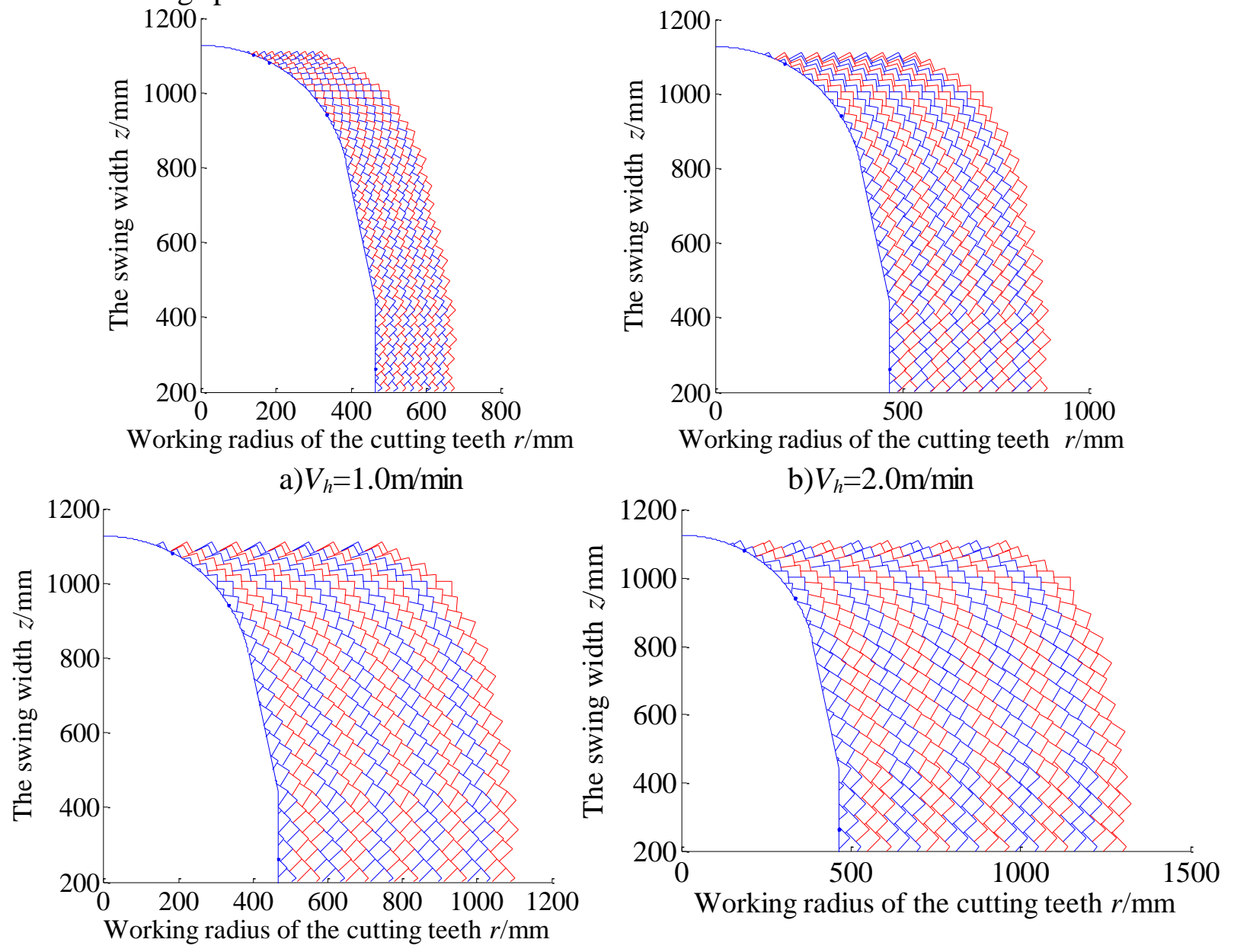

c) $V_{h}=3.0 \mathrm{~m} / \mathrm{min}$

d) $V_{h}=4.0 \mathrm{~m} / \mathrm{min}$

FIGURE.5 Cutting patterns under swing condition with different swing speeds

\section{Summary}

In this paper, simulation research on the cutting patterns for cutting head of longitudinal axial roadheader is done under drilling condition and swing condition. The cutting patterns which reflects the cutting performance of the cutting head are drawn. The cutting process of cutting head can be intuitively obtained and the groove shape can be clearly observed. The effects on drilling condition with the changing parameters of deflection angle $\alpha$ and drilling speed $V_{\mathrm{z}}$ and the effects on swing condition with the changing parameters of deflection 
angle $\alpha$ and swing speed $V_{\mathrm{h}}$ are analyzed. The research provides a basis for the design, analysis and optimization of the cutting head of longitudinal axial roadheader.

\section{References}

[1] Xiaohuo Li. The key technology research of Roadheader Cutting Head [M]. BeiJing: Mechanical industry Press, 2008. (In Chinese)

[2] Tiryaki B, Ayhan M, Hekimoglu O Z. A new computer program for cutting head design of roadheaders and drum shearers $[\mathrm{C}] / / 17$ th International Mining Congress and Exhibition of Turkey. 2001: 655-662.

[3] Somanchi S, Kecojevic V, Kozminski T. Advance design of lacing and breakout patterns for shearer drums[J]. Mining Technology, 2005, 114(2): 118-124.

[4] Sun Y, Li X S, Shao W. Influence of cutting parameters and interactions on the depth of cut in continuous mining operation[J]. Advanced Materials Research, 2012, 538: 1422-1428.

[5] Xiubao Shi, Miqi Lu, Zhijuan Cao. Simulation Research of Cutting Process of Cutting Head of Longitudinal-axial-roadheader Based on Matlab[J]. Industry and Mine Automation, 2010 (1): 37-39(In Chinese)

[6] Cong r, BaiX, Qao Q. Calculation on filing thickness of excavating tooth using filing diagram [J]. Chinese Journal of Construction Machinery, 2007, 4: 027. (In Chinese)

[7] Xiao-hong M A. Visual Design of Breakout Pattern on Continuous Miner Cutting Drum[J]. Coal Mine Machinery, 2008, 6: 018. (In Chinese) 